\title{
Erratum to: Coming of Age on the Margins: Mental Health and Wellbeing Among Latino Immigrant Young Adults Eligible for Deferred Action for Childhood Arrivals (DACA)
}

\author{
Rachel Siemons $^{1,2,3}$ - Marissa Raymond-Flesch ${ }^{4}$. Colette L. Auerswald ${ }^{1,2,3}$. \\ Claire D. Brindis ${ }^{4}$
}

Published online: 23 April 2016

(C) Springer Science+Business Media New York 2016

\section{Erratum to: J Immigrant Minority Health DOI 10.1007/s10903-016-0354-x}

The second author's family name was erroneously submitted and published as Raymond-Flesh, instead of Raymond-Flesch. This erratum is issued to fix the error.

The online version of the original article can be found under doi:10.1007/s10903-016-0354-x.

\section{Claire D. Brindis}

Claire.Brindis@ucsf.edu

1 University of California, Berkeley, Berkeley, CA, USA

2 University of California, San Francisco, San Francisco, CA, USA

3 Joint Medical Program, UC Berkeley School of Public Health, Berkeley, CA, USA

4 Philip R. Lee Institute for Health Policy Studies, Division of Adolescent \& Young Adult Medicine, Department of Pediatrics, University of California, San Francisco, 3333 California Street, Suite 265, San Francisco, CA 94118, USA 